\title{
Nondestructive quantitative characterisation of material phases in metal additive manufacturing using multi-energy synchrotron $\mathrm{X}$-rays microtomography
}

\author{
Matheus S. Xavier ${ }^{1,2}$ (D) . Sam Yang ${ }^{2} \cdot$ Christophe Comte $^{3} \cdot$ Alireza Bab-Hadiashar $^{1} \cdot$ Neil Wilson $^{4} \cdot$ Ivan Cole $^{1}$
}

Received: 29 November 2018 / Accepted: 21 October 2019 / Published online: 10 December 2019

(C) The Author(s) 2019

\begin{abstract}
Metal additive manufacturing (MAM) has found emerging application in the aerospace, biomedical and defence industries. However, the lack of reproducibility and quality issues are regarded as the two main drawbacks to AM. Both of these aspects are affected by the distribution of defects (e.g. pores) in the AM part. Computed tomography (CT) allows the determination of defect sizes, shapes and locations, which are all important aspects for the mechanical properties of the final part. In this paper, data-constrained modelling (DCM) with multi-energy synchrotron X-rays is employed to characterise the distribution of defects in 316L stainless steel specimens manufactured with laser metal deposition (LMD). It is shown that DCM offers a more reliable method to the determination of defect levels when compared to traditional segmentation techniques through the calculation of multiple volume fractions inside a voxel, i.e. by providing sub-voxel information. The results indicate that the samples are dominated by a high number of small light constituents (including pores) that would not be detected under the voxel size in the majority of studies reported in the literature using conventional thresholding methods.
\end{abstract}

Keywords Additive manufacturing - Laser metal deposition · X-ray computed tomography (XCT) ·

Data-constrained modelling (DCM) - Defects

\section{Introduction}

Additive manufacturing (AM) is defined as "a process of joining materials to make objects from 3D model data, usually layer upon layer, as opposed to subtractive manufacturing methodologies" (ASTM F2792-12a). The main difference between the AM processes is the method of producing individual layers [1-3]. Metal additive manufacturing (MAM) uses a laser or an electron beam to melt metal powder or wire as feedstock to build parts,

Sam Yang

Sam.Yang@csiro.au

Matheus S. Xavier

matheus.santos.xavier@gmail.com

1 School of Engineering, RMIT University, Melbourne, 3000, Australia

2 CSIRO Manufacturing, Clayton, 3168, Australia

3 CSIRO Manufacturing, Lindfield, 2070, Australia

4 Romar Engineering, Sefton, 2162, Australia commonly with steel, aluminium and titanium alloys [4, 5], and has found applications in the biomedical [6, 7] and aerospace [8, 9] industries. Other fields that have introduced MAM include automobile, energy and defence industries [10, 11]. In particular, 316L stainless steel (SS) has been well-established in additive manufacturing due to its corrosion resistance, excellent mechanical properties and very good processability [12-14]. As outlined by various authors $[4,5,15,16]$, the advantages of AM include the ability to build complex features (free form capability), hollow (unsupported) structures (weight savings) and high precision parts with a lower number of manufacturing steps and high buy-to-fly ratios; tool-less manufacturing, just-in-time manufacturing and reduction of lead time; multimaterial manufacturing, remanufacturing and repair of damaged, worn-out or corroded parts.

There are a number of challenges for AM to establish itself as a core technology. In this context, quality and repeatability are regarded as the two main drawbacks of AM [15, 17-20]. Both of these aspects are affected by the porosity level and distribution in the part. The presence of porosity deteriorate the mechanical properties $[21,22]$, especially fatigue performance $[23,24]$. Thus, the 
manufacture of parts with high density is typically the initial aim in AM process optimisation [5]. A variety of methods are available for the detection of defects after the part has been produced and can be classified into two categories:

(1) Destructive methods: such as cutting, grinding and polishing of the part, which is then analysed using optical or scanning electron microscopes [25, 26]. This approach, besides not being economically favourable and being time-consuming, is limited to some sections of the specimen [27]. Ahsan et al. [28] emphasises that optical and scanning electron microscopy are very good techniques for microstructure analysis but have the drawback of only providing information on discrete planes. Consequently, since porosity is not uniformly distributed, the cross-section could be selected at a region that is free of pores, for example, and therefore not representative of the entire part. Furthermore, the specimen preparation, i.e. grinding and polishing, may affect the sizes and shapes of pores due to metal smearing [26, 29].

(2) Nondestructive methods: such as density measurements using the Archimedes method or gas pycnometry $[26,30]$, ultrasonic methods $[31,32]$ and computed tomography (CT) $[15,33]$. The most common nondestructive methods for the evaluation of porosity in AM samples are the Archimedes method and CT [34, 35]. The Archimedes method allows the determination of the density of the part by measuring the mass of the part in air and in a fluid of known density. From the determined density and the nominal density of the material, an average porosity value can be determined for the whole sample [26, 36]. Spierings et al. [27] suggest that this is the most reliable, economic and fast procedure for porosity quantification. On the other hand, du Plessis et al. [35] discussed some of the problems associated with the method, such as the attachment of air bubbles on the surface resulting in lower density, open porosities could be filled with water and affect the measurement, inclusions could increase the measured density and the assumed nominal density may be incorrect for alloys with varying compositions.

Size, shape and location of pores play a significant role on the mechanical properties and part performance. Therefore, the overall porosity (Archimedes method or pycnometry) does not provide sufficient information to characterise the influence of porosity [29, 34, 35, 37]. De Chiffre et al. [38] highlighted CT as the only method for nondestructive analysis of internal features and porosities. Since the introduction of microcomputed tomography ( $\mu$ XCT) by Flannery et al. [39] in 1987, the method has evolved to a quantitative technique [40] and has found widespread application in materials science [41-43]. A tutorial review on X-ray microtomography is available in Landis, Keane [44], wherein the authors emphasise that the technique is complementary to high-resolution metallographic analysis and lower resolution ultrasonic imaging.

Microcomputed tomography has become an important tool in AM, especially considering its ability to manufacture complex internal features and its high precision [34, 35]. Despite the progress in the application of CT in AM, the resolution in X-ray tomography is limited by the voxel size and is affected by several factors such as blurring from a finite X-ray source, scatter of X-ray photons, beam hardening and mechanical errors from tilting during imaging [45]. Maskery et al. [29] showed that the choice of thresholding method highly influences the pore sizes and shapes. The authors state that manually adjusting the automatic threshold by $5 \%$ changed the mean porosity by $10 \%$; consequently, they argue robust image analysis procedures for the thresholding should be adopted. Cai et al. [36] point out that the resolution of the XCT imaging is limited by both the voxel size and the specimen size (small specimens allow higher resolution to detect smaller defects). They note that global thresholding and locally adaptive segmentation produce very different porosity results and suggest a number of image processing steps before applying the thresholding. Salarian, Toyserkani [46] demonstrated that the nano-CT detects a larger amount of pores since pores smaller than $216 \mu \mathrm{m}^{3}$ are not detected by the micro$\mathrm{CT}$, this resulted in a slightly smaller density, which is argued as critical for demanding applications. The nano-CT also allows better determination of edges of pores, providing a more accurate segmentation.

From the previous discussion, some issues are yet to be addressed in order to improve the potential of computed tomography in detecting defects in metal AM: (1) the limited resolution of the scans, (2) lack of thresholding robustness (i.e. different results due to the effects of colour thresholding and CT artefacts and noise), (3) incapability of differentiating between pores and inclusions for conventional segmentation techniques. In order to address some of these issues, synchrotronbased microtomography ( $\mu \mathrm{SXCT}$ ) can be used. Among the microtomography techniques, it provides the best speed, spatial resolution and signal-to-noise ratio as a result of the high intensity, monochromatic, practically parallel and tunable beams [47-49]. The energy tunability, in particular, can be used to perform multi-energy CT, offering the possibility to distinguish material compositions with similar attenuations for a single energy [50, 51].

Conventional thresholding techniques cannot distinguish features smaller than a voxel size [27, 29, 45, 46, 52]. In these studies, a pore with the size of a voxel could be 
generated by noise; thus, most studies consider a lower pore size cutoff of at least $2 \times 2$ pixels $(2 \times 2 \times 2$ voxels $)$. This cutoff is even higher for the determination of pores shapes. DCM (data-constrained modelling), on the other hand, enables more accurate determination of the composition of a sample, providing more detailed information and allowing to calculate materials distributions below $\mathrm{CT}$ resolution, i.e. inside a voxel $[50,51,53]$. As discussed in Trinchi et al. [51], using one or more CT datasets at different energies, DCM takes advantage of the energy-dependent material properties to generate voxels that are not single valued (as in traditional segmentation), but instead consist of multiple compositions, including pores.

The nonlinear optimisation in DCM is equivalent to adjusting the volume fractions of each composition in the voxels in order to minimise the difference between the theoretical and measured linear absorption coefficients and to maximise the Boltzmann distribution probability [53, 54]. Consequently, it is possible to accurately determine the distribution of pores and inclusions in the sample by taking into account even those that are smaller than the imaging resolution. DCM has been applied to a number of studies in materials characterisation, such as oil and gas reservoir rocks [55, 56], corrosion inhibitors [57] and cold-sprayed titanium parts [58].

The paper is organised as follows. A description on the sample preparation, imaging procedures (including both multi-energy synchrotron CT and conventional CT), hardness testing and SEM/EDS analysis is provided in Section 2. In Section 3, the levels and distributions of defects in the samples by both CT techniques are discussed. These distributions are then correlated with the hardness and chemical compositions of the samples. In Section 4, we draw some conclusions on the results presented. Finally, this is followed by acknowledgements and references.

\section{Methodology}

\subsection{Sample preparation}

In this study, laser metal deposition was employed to build parts with 316L SS powder. In LMD (Fig. 1), a part is built by melting a surface with a laser and simultaneously applying the metal powder through a coaxial or multi-jet nozzle $[1,2,5]$. The powder composition is given in Table 1 . The sieve analysis reveals the powder size to be in the range 36-125 $\mu \mathrm{m}$, with average size of $70 \mu \mathrm{m}$.

Two samples with cylindrical shape and size of $2 \mathrm{~mm}$ (diameter) $\times 6 \mathrm{~mm}$ (height) were machined for analysis. Sample 1 was taken in the core of the part, where the deposition process was well-established and the resulting material expected to be uniform. The corresponding

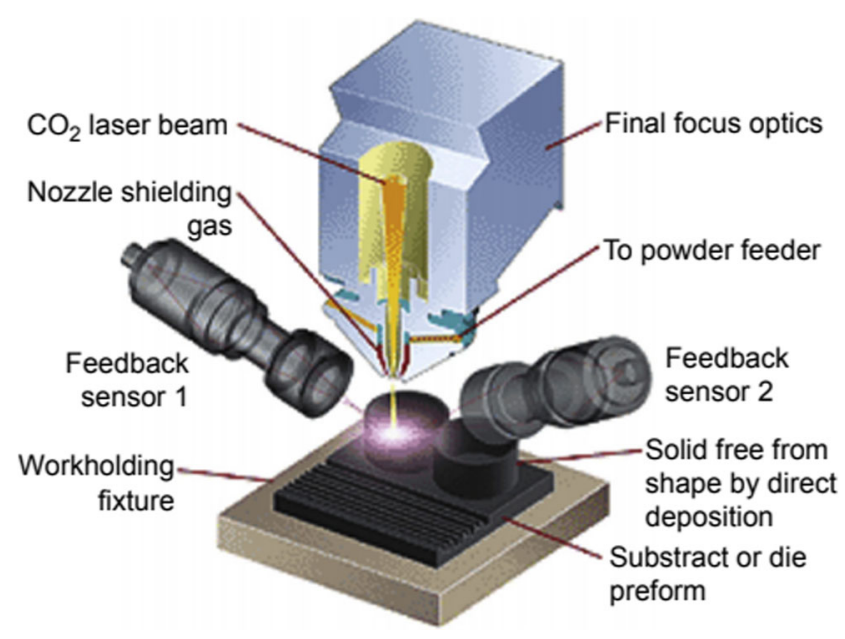

Fig. 1 Laser metal deposition [1]

deposition conditions as recommended by the manufacturer are summarised in Table 2. Only the laser power was adjusted during the deposition process to maintain the building rate and the shape of the build (the feedback sensor available in the machine was deactivated). For comparison, sample 2 was machined within the disposable first layers of the build intended to anchor the $316 \mathrm{~L}$ part to the substrate, where both the proximity of the mild steel substrate and a higher laser power $(990 \mathrm{~W})$ are expected to produce a less consistent material.

\subsection{Synchrotron CT: image acquisition, reconstruction and $\mathrm{DCM}$}

The imaging was performed at the Imaging and Medical beamline (IMBL) at the Australian Synchrotron. The synchrotron X-rays passed through the sample, hitting a scintillator, which converted the $\mathrm{X}$-rays to visible light captured by the Ruby detector. The sample to detector distance was $28.5 \mathrm{~cm}$ and the resulting pixel size is $5.97 \mu \mathrm{m}$. For each respective energy, 3600 images were generated by scanning the samples $180^{\circ}$ with an angle step of $0.05^{\circ}$. Before and after the imaging for each energy, 100 dark field images and 100 flat field images were also taken.

Table 1 Chemical composition of 316L powder

\begin{tabular}{ll}
\hline Element & Specification $(\%)$ \\
\hline Chromium & 16.9 \\
Nickel & 13.0 \\
Molybdenum & 2.6 \\
Manganese & 1.5 \\
Silicon & 0.8 \\
Carbon & 0.006 \\
Iron & Balance
\end{tabular}


Table 2 AM build parameters

\begin{tabular}{ll}
\hline AM technology & Laser metal deposition (LMD) \\
Machine & DMG Mori Lasertec 65 3D \\
Laser power & $850 \mathrm{~W}$ \\
Laser velocity & $880 \mathrm{~mm} / \mathrm{min}$ \\
Laser spot size & $1.6 \mathrm{~mm}$ \\
Layer thickness & $1 \mathrm{~mm}$ \\
Substrate & Mild steel, $150 \times 150 \times 25 \mathrm{~mm}^{3}$ \\
Mass flow rate & $7.7 \mathrm{~g} / \mathrm{min}$ (powder) and $\left.6 \mathrm{~L} / \mathrm{min}^{(\arg g o n}\right)$ \\
\hline
\end{tabular}

The projection images were imported into X-TRACT [59]. They were then pre-processed using trimming to reduce the raw images to the areas corresponding to the sample, flat field correction and dark current subtraction for background correction, a polar filter size of 9 for ring artefact removal, and phase retrieval using the Paganin's algorithm [60]. For the phase-retrieval step, the $\delta / \beta$ ratio ( $\delta$ and $\beta$ are the real and imaginary parts of the complex refractive index, respectively) was calculated based on the material composition and corresponding X-ray energy to minimise edge enhancement without loss of resolution, resulting in 219 for $70 \mathrm{keV}$ and 315 for $90 \mathrm{keV}$. After pre-processing, the data was reconstructed using a standard filtered backprojection (FBP) parallel-beam algorithm [61].

In multi-energy $\mathrm{CT}$, the energies are selected to maximise the contrast between the different phases in the sample, i.e. minimise the linear dependence between the CT datasets, and therefore maximise noise tolerance [51, 57]. The penetration of the $60 \mathrm{keV} \mathrm{X}$-rays was found to be below $30 \%$ in the mid regions of the samples; hence, to accomplish higher contrast the $70 \mathrm{keV}$ and $90 \mathrm{keV}$, reconstructed datasets were imported into DCM. In order to minimise artefacts from the CT, the topmost and bottommost layers were excluded and 850 reconstructed slices from each energy were considered. Furthermore, the experimental attenuation of 316L SS was lower than the theoretical attenuation. Hence, the measured attenuation was multiplied by 1.18 and 1.15 for the 70 and $90 \mathrm{keV}$ datasets, respectively.

In DCM, three groups have been determined based on the EDS analysis and the attenuation values normalised to the bulk material $\left(\mu_{\text {norm }}\right)$ : (1) pores and silicon oxide $\left(\mu_{\text {norm }} \approx 0.1\right)$ : pores and $\mathrm{SiO} 2$; (2) bulk material (316L SS); (3) manganese and chromium oxides and carbides $\left(\mu_{\text {norm }} \approx\right.$ $0.5)$ : $\mathrm{Cr} 2 \mathrm{O} 3, \mathrm{MnO}, \mathrm{Cr} 23 \mathrm{C} 6$ and $\mathrm{Mn} 23 \mathrm{C} 6$.

For each of these groups, an equivalent molecular formula and average density are calculated assuming the same proportion for every one of the elements in the group. These are then defined as three channels in DCM (each channel in DCM is an internal holder for data values). It is noteworthy that even though data from the first group will be referred to as pores, it may actually incorporate silicon inclusions since porosity and low attenuation inclusions (light constituents) cannot be distinguished in CT.

As described in [53, 54], for each of the $i$ th voxels in the sample, the nonlinear optimisation consists of minimising the objective function in (1), subject to the constraints in (2):

$$
T_{i}=\sum_{\varepsilon}\left[\mu^{p}(\varepsilon) v_{i}^{p}+\mu^{b}(\varepsilon) v_{i}^{b}+\mu^{o}(\varepsilon) v_{i}^{o}-\bar{\mu}_{i}(\varepsilon)\right]^{2}+E_{i}
$$

$\left\{\begin{array}{c}0 \leq v_{i}^{p}, v_{i}^{b}, v_{i}^{o} \leq 1 \\ v_{i}^{p}+v_{i}^{b}+v_{i}^{o}=1\end{array}\right.$

where $v_{i}^{p}, v_{i}^{b}$ and $v_{i}^{o}$ represent the volume fractions of pores/low attenuation inclusions, bulk material and oxides/carbides, respectively; $\mu^{p}(\varepsilon), \mu^{b}(\varepsilon)$ and $\mu^{o}(\varepsilon)$ are the linear absorption coefficients of pores/low attenuation inclusions, bulk material and oxides/carbides, respectively, for each of the energies $\left(\varepsilon_{1}=70 \mathrm{keV}\right.$ and $\left.\varepsilon_{2}=90 \mathrm{keV}\right)$; $\bar{\mu}_{i}(\varepsilon)$ is the total linear absorption coefficient at the voxel for the respective energy; and $E_{i}$ is the phenomenological interaction energy. The linear absorption coefficients were $\mu^{p}\left(\varepsilon_{1}\right)=0.288 \mathrm{~cm}^{-1}, \mu^{b}\left(\varepsilon_{1}\right)=6.690 \mathrm{~cm}^{-1}$ and $\mu^{o}\left(\varepsilon_{1}\right)=$ $3.891 \mathrm{~cm}^{-1}$ for $70 \mathrm{keV}$ and $\mu^{p}\left(\varepsilon_{2}\right)=0.238 \mathrm{~cm}^{-1}, \mu^{b}\left(\varepsilon_{2}\right)=$ $3.793 \mathrm{~cm}^{-1}$ and $\mu^{o}\left(\varepsilon_{2}\right)=2.291 \mathrm{~cm}^{-1}$ for $90 \mathrm{keV}$, based on the density values available in [62].

\subsection{Conventional CT: image acquisition, reconstruction and thresholding}

The samples were imaged using Skyscan 1275 X-ray microtomography from Bruker at a voxel size of $6 \mu \mathrm{m}$ and $100 \mathrm{kV}$. In order to reduce the beam hardening artefact, a copper filter of a 1-mm thickness was used. The sample was rotated $360^{\circ}$ at a rotation step of $0.4^{\circ}$ and a number of 4 frames being acquired for each step in order to reduce noise.

Images were reconstructed using NRecon. The images were pre-processed during reconstruction through a beamhardening correction of $30 \%$ (as suggested by the standard recipe from Bruker) and a filter of 9 (same as the filter analysed for the synchrotron CT) for ring artefact removal. For the porosity analysis, the reconstructed slices were imported into CTan. Firstly, a range of 800 slices that do not contain clear visual artefacts from the CT were selected for each sample. After that, circular regions of interest were selected at the uppermost and undermost slices for each sample, which were then interpolated to create a cylindrical volume of interest inside the sample.

The most common thresholding techniques for analysis of porous media are (global/local) manual thresholding, Otsu's thresholding and adaptive thresholding, as discussed 
in Iassonov et al. [63]. These three methods were then employed in the sample after a non-local mean 3D filtering and an unsharp mask filtering, as suggested by [36, 46] in similar metal additive manufacturing studies. The mean filter removes noise while preserving significant features and the unsharp mask filter enhances edges without overly exaggerating the noise and partially corrects for the smoothing in the tomographic reconstruction [64]. For the manual thresholding, the dataset was segmented into bulk material and pores using a threshold of 170 . This value was selected to show the best similarity with the inclusions and pores that can be clearly visualised in sample 2 . The same value was applied to sample 1 .

A second instrument for conventional microtomography with a voxel size of $4 \mu \mathrm{m}$ was used to evaluate the effect of smaller voxel size in the accuracy of detecting the porosity distribution and to validate the results obtained with DCM. The samples were imaged using a GE Phoenix v|tome $\mid \mathrm{x}$ $240 \mathrm{kV}$. Images were reconstructed and analysed using VGStudio MAX 3.0. The VGDefX algorithm was employed since it is more sophisticated than the "only thresholding" algorithm and allows for grey value variations, noise reduction and detection of open pores. In this analysis, automatic surface determination and then an autothreshold were used. Once again, a filtering step was added to remove noise and ring artefact and streak artefact removal were also employed. In the detection of porosity, a minimum size of 8 voxels was considered.

\subsection{Hardness test and SEM/EDS analysis}

Before proceeding with hardness testing, the samples were prepared using a Struers-Hexamatic machine with a long method for high alloy steels. It consisted of grinding with $\mathrm{SiC}$ foil \#220, fine grinding with MD-Largo, three diamond polishing steps (MD-Mol, MD-Nap and MD-Chem) and cleaning at the end of each grinding and polishing step.

For the hardness measurement, a TI950 Triboindenter (Hysitron) with a Berkovich3 tip was used with the polished samples. The parameters were peak force of $10,000 \mu \mathrm{N}$ and dwell time of $10 \mathrm{~s}$ (same time for loading and unloading), resulting in a depth of penetration $\left(h_{c}\right)$ of approximately $330 \mathrm{~nm}$. For sample 1, 25 indentations in the centre of the sample along the $Z$-direction were made, while 50 indentations were used for sample 2 in order to more accurately analyse the non-uniform distribution of inclusions and porosity in this specimen.

A Philips XL30 scanning electron microscope (SEM) equipped with an Oxford XMAX20 detector was used to perform energy dispersive X-ray spectroscopy (EDS) analysis with the AZtec software. EDS allows determining the chemical composition of the polished samples and evaluating possible compositional changes during manufacturing, particularly for the inclusions formed during AM. The parameters were accelerating voltage of $30 \mathrm{kV}$ and spot size of 5.

\section{Results and discussion}

\subsection{Multi-energy synchrotron CT and DCM}

After the nonlinear optimisation in DCM, the 3D images of the samples are shown in Fig. 2. Display intensities have been adjusted for better visibility. Light constituents (pores and silicon inclusions) are displayed as green, bulk material as blue and oxides and carbides as red. For sample 1 (Fig. 2a), CT suggests grain growth in the build direction with the light constituents mainly distributed along the grain boundaries. The presence of elongated grains (epitaxial growth) roughly parallel to the build direction is a result of the steep temperature gradient created by the directed local heat source [2], i.e. the heat conduction in the build direction is typically higher than in the build plane (unidirectional heat transfer and cooling) $[1,5]$. In addition, the existence of $\mathrm{Si}$ along the grain boundaries has also been reported in [65] and might be related to thermal segregation. For sample 2 (Fig. 2b), the manganese and chromium carbides and oxides are found concentrated in four regions, with light constituents appearing as clouds around them. The distances between these four regions are approximately $0.9 \mathrm{~mm}$, i.e. the layer thickness. Therefore, inclusions can be associated with the oxidation that developed during the fabrication of the sample since the layers were exposed to air during cooling. Notice that these inclusions were only present for the layers in the proximity of the build plate and, consequently, can be attributed to the influence of the mild steel in the building process.
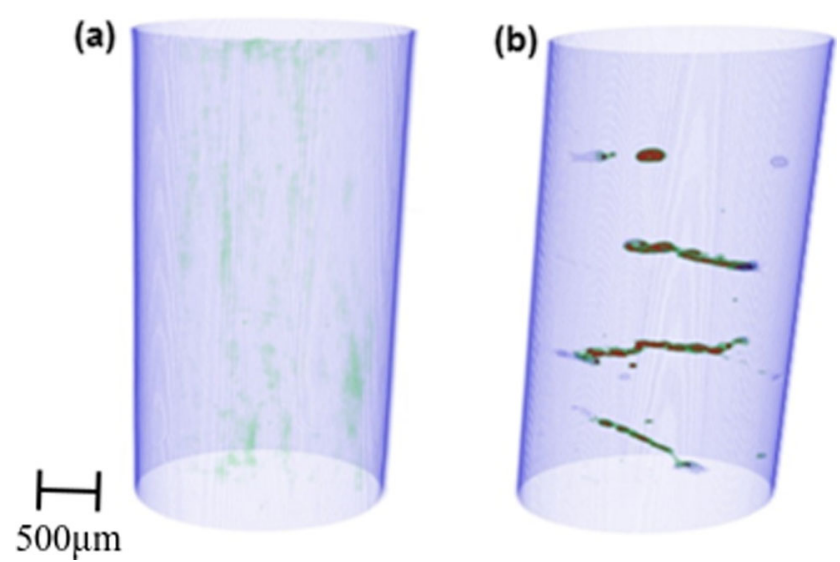

Fig. 2 3D visualisation of samples 1 (a) and 2 (b) in DCM. Light constituents (pores and silicon inclusions) are displayed as green, bulk material as blue and oxides and carbides as red 
To analyse the distribution of defects based on the compositional map provided by DCM, C++ plugins were developed in Microsoft Visual Studio. These plugins were then incorporated into the computation method in DCM. The first of these plugins determines the average distribution of light constituents in each layer. The uppermost and undermost fifty layers were removed from this analysis since they have shown high concentration of defects which are attributed to artefacts from the CT. Figure 3 shows that sample 1 (grey line) has a lower level of light constituents, with these being uniformly distributed along the sample. In contrast, sample 2 (black line) shows that light constituents are mostly concentrated in four locations, corresponding to the regions in which inclusions occur.

One important parameter in quantitative analysis of defects is the defect size. As discussed earlier, traditional segmentation methods assign a single particular value for a voxel and therefore no features (e.g. pores) can be reliably found under the voxel size. DCM, on the other hand, determines partial volume fractions for each voxel, which allows the determination of defect sizes below the voxel size. The only restriction here is the noise in the CT data. In order to account for the noise, the defect sizes are determined only if they correspond to at least $10 \%$ of the volume fraction of the voxel.

In the quantification of sizes and shapes of light constituents, an arbitrary value of 0.30 was chosen for the connectedness parameter in the clustering analysis. As described in Ren et al. [58], this means that light constituents in neighbouring voxels are connected when both of their volume fractions are above this value. Using the threshold of 0.3 , no light constituent clusters were found for sample 1 and, consequently, the determination of light constituent shapes is not possible. However, 40 light constituents were found with a size ranging from 3 to $4 \mu \mathrm{m}$ (those with volume fractions below 0.3). The light constituent sizes histogram for sample 2 is shown in Fig. 4. This figure shows that the majority of light constituents are quite small, i.e. $99.5 \%$ of the light constituents are smaller

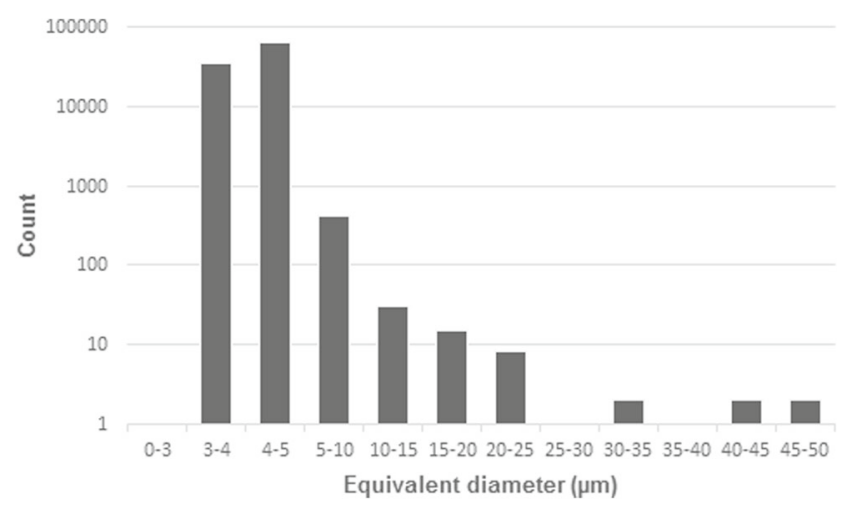

Fig. 4 Light constituent sizes for sample 2 using DCM

than $5 \mu \mathrm{m}$. Moreover, for sample 2630 clusters were found and a plugin was developed to calculate their surface areas. Then, it is possible to determine the sphericity $S[52,66]$, which is given by the ratio of the surface area of a sphere having the same volume $V$ as the light constituent to the surface area $A$ of the light constituent, i.e.:

$S=\frac{\pi^{1 / 3}(6 V)^{2 / 3}}{A}$

The sphericity $S$ takes a value from 0 to 1 , with 1 representing a perfect sphere and lower values indicating irregularly shaped light constituents. The sphericity histogram for sample 2 is shown in Fig. 5. Two distributions are shown: the grey one represents the sphericity for all defect clusters and the black one represents the sphericity only for a volume threshold equivalent to 5 voxels. It is clear that, while the small light constituents have a quite spherical shape $(\mathrm{S} \approx$ 0.75), the largest light constituents have an irregular shape $(\mathrm{S} \approx 0.45)$.

These findings are in agreement with previous studies reported in the literature [29, 45, 66, 67], i.e. the light constituents (including pores) are not uniformly distributed over the sample, with large light constituents being elongated in the $x-y$-plane, which is believed to be related to the layerwise manufacturing process in additive
Fig. 3 Light constituent distribution in the build direction for sample 1 (grey) and 2 (black)

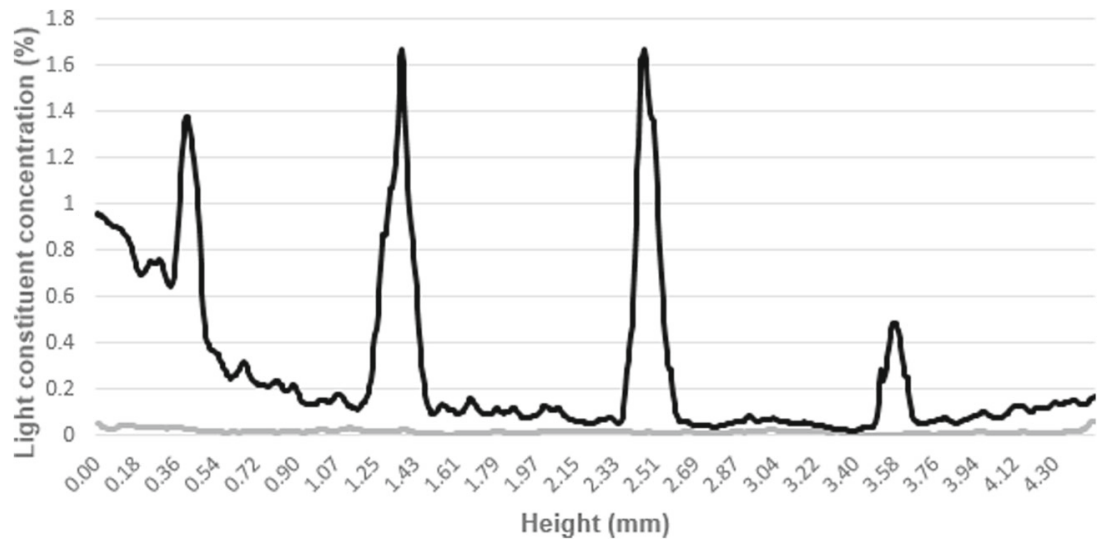




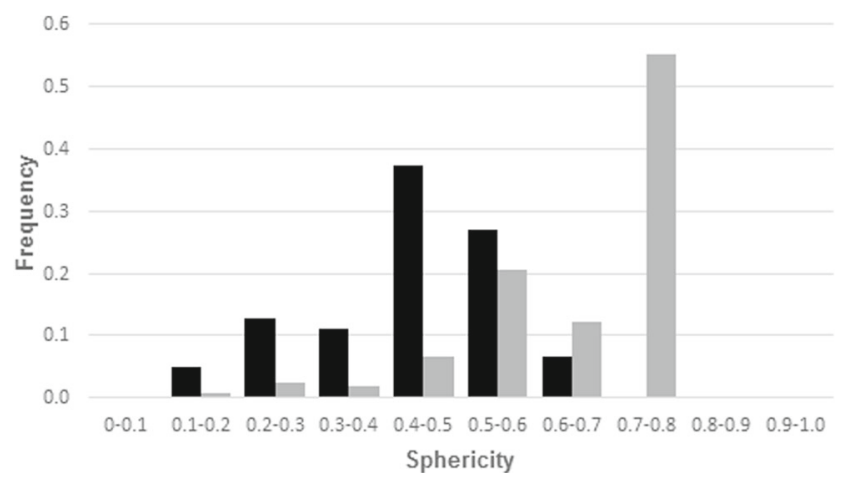

Fig. 5 Sphericity for pores in sample 2 using DCM. The grey histogram represents all clusters and the black histogram only includes clusters with volume above 5 voxels

manufacturing. The majority of light constituents are small and spherical, while the few large light constituents (possibly associated with lack of fusion) have irregular shape (low sphericity or high aspect ratio). Cunningham et al. [37] found that the large pores were concentrated at the surface of the melt pool area. Using DCM, it is seen that the majority of large, irregularly shaped light constituents are located near the melting areas.

As reported in Slotwinski et al. [67], for sample 2, the distribution of light constituents has significant variation along the sample and there is more variability in the $z$ direction (build direction) than in the $x$ - and $y$-directions. However, in Cai et al. [36], the porosity was uniformly distributed in the build direction, which is the behaviour exposed by sample 1. Therefore, it is evident that the amount of light constituents varies among the samples due to processing parameters. In this study, in particular, this was associated with the location in regard to the build plate and the influence of the mild steel in increasing the levels of light constituent and inclusions.

\subsection{Conventional microtomography}

Firstly, we point out that it is not possible to distinguish between inclusions and porosity using conventional (greylevel) thresholding methods. For this reason, the pores found with conventional thresholding will be referred to as "detected pores". The porosity values in the samples for DCM and the other segmentation methods in this study are shown in Table 3. This porosity corresponds to the distribution of light constituents (low attenuation inclusions and pores) in DCM and "detected pores" in conventional thresholding. For the lab-based microtomography at $6 \mu \mathrm{m}$, it is evident that the levels of porosity determined using manual thresholding are much closer to the ones determined using DCM. Indeed, Otsu's thresholding and adaptive thresholding did not show robustness in the analysis for the $316 \mathrm{~L}$ sample. As it can be seen in Fig. 6a-d, which is a representation of the thresholding techniques on the reconstructed slices for sample 2, the automatic Otsu and adaptive thresholdings incorrectly determine a much higher amount of porosity. Based on the aforementioned, further analysis of individual objects, i.e. "detected pore" sizes and sphericities, was only performed for the manual thresholding.

The "detected pore's" equivalent diameter and sphericity histograms for both samples are shown in Figs. 7 and 8 , respectively. In agreement with the results from DCM, sample 2 shows a much higher porosity level. The samples are dominated by small "detected pores" with quite spherical shape, possibly associated with gas porosity entrapped during powder production. However, sample 2 also contained large "detected pores", mostly with irregular shapes.

Due to the fact that grey level thresholding cannot efficiently distinguish between pores and inclusions, it is likely that inclusions have been lumped with pores, resulting in the "detected pores" larger than $50 \mu \mathrm{m}$ that have been identified with conventional thresholding but not with DCM. Furthermore, since a 6- $\mu \mathrm{m}$ voxel size was used, the "detected pore" sizes below approximately $12 \mu \mathrm{m}$ cannot be considered reliable data. For this reason, only the "detected pores" with size higher than $12 \mu \mathrm{m}$ are considered for the sphericity histogram in Fig. 8.

For the lab-based microtomography at $4 \mu \mathrm{m}$, the software VGStudio MAX 3.0 offers two automatic thresholding algorithms: "only thresholding" and "VGDefX". Both of these techniques are considered (Table 3), however, for the reasoning presented in Section 2.3, the VGDefX algorithm is selected for analysis of "detected pores" sizes and shapes. With the VGDefX method, two autothreshold modes are available: deviation and interpolation. The statistics for the "detected pores" using these two modes with standard parameters did not exhibit much variation. The

Table 3 Overall porosity values (\%) obtained with DCM and different thresholding techniques

\begin{tabular}{lllllll}
\hline $\begin{array}{l}\text { Software } \\
\text { Method }\end{array}$ & $\begin{array}{l}\text { DCM } \\
\text { Nonlinear optimisation }\end{array}$ & $\begin{array}{l}\text { CTan } \\
\text { Manual thresholding }\end{array}$ & Otsu thresholding & Adaptive thresholding & VGDefX & Only thresholding \\
\hline Sample 1 & 0.019 & 0.000 & 48.829 & 11.471 & 0.004 & 0.001 \\
Sample 2 & 0.281 & 0.381 & 40.276 & 10.607 & 0.306 & 0.205 \\
\hline
\end{tabular}


Fig. 6 a Reconstructed slice 817 , b slice 817 with manual global thresholding, c slice 817 with automatic Otsu thresholding and d slice 817 with adaptive thresholding
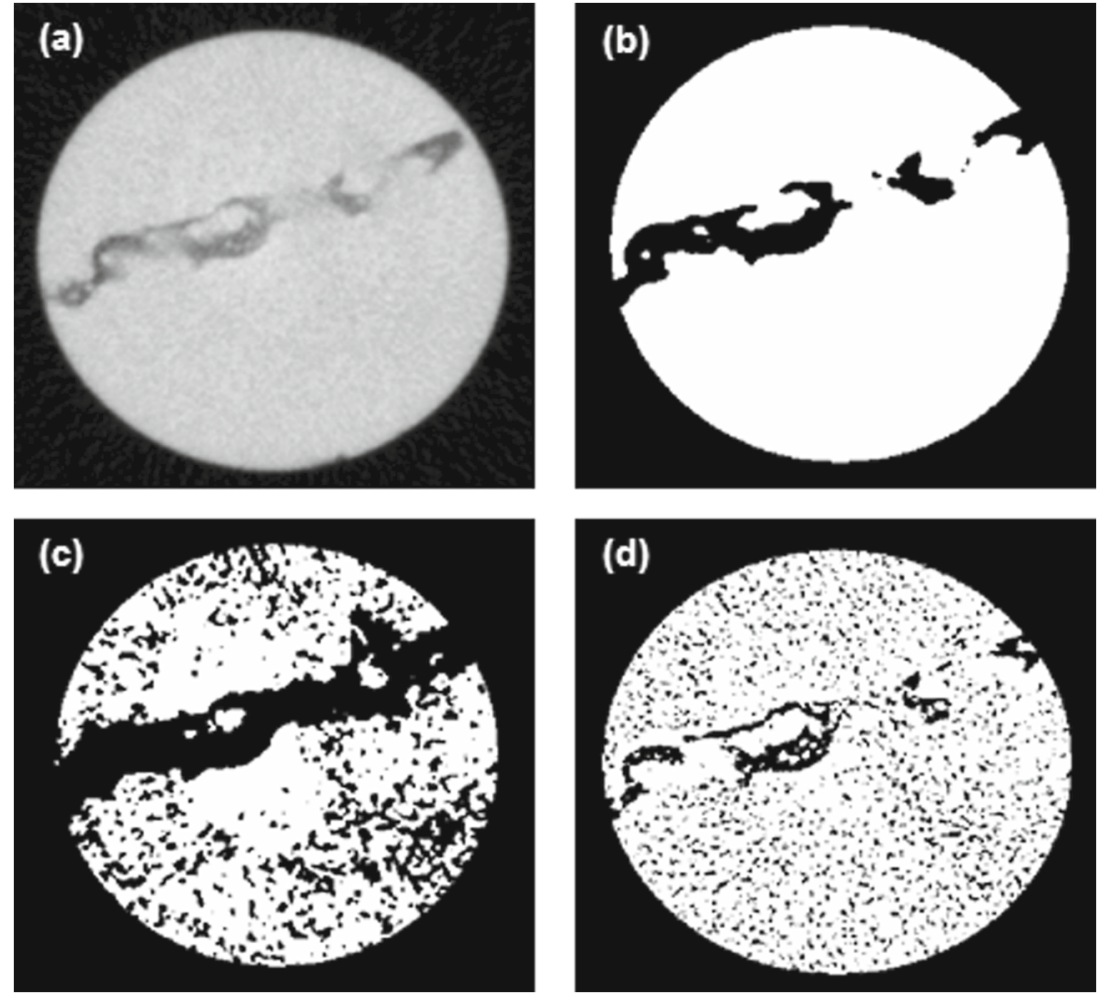

$3 \mathrm{D}$ visualisation of the porosity distribution is presented in Fig. 9.

The "detected pore" sizes histogram is shown in Fig. 10. Once again, we see that sample 1 is dominated by relatively small "detected pores", while sample 2 also has large "detected pores". In particular, the two largest "detected pores" (> $200 \mu \mathrm{m}$ ) have very irregular shape, i.e. sphericity of approximately 0.15 (Fig. 12). Comparison of Figs. 2 and 9 shows that the algorithm is unable to distinguish between the inclusions and porosity in sample 2; consequently, the interlayer "detected pores" are incorrectly determined to be very large.

From the results, it is evident that DCM has provided more reliable results for the $\mathrm{CT}$ scan at $6 \mu \mathrm{m}$. Instead

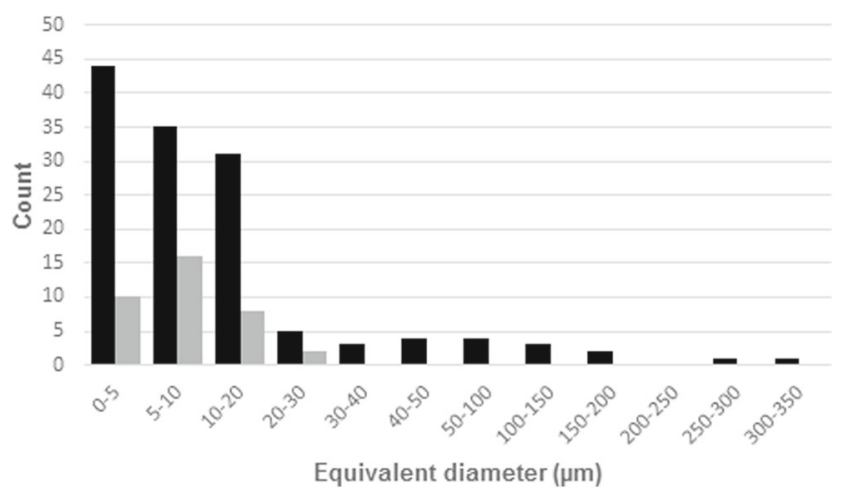

Fig. 7 "Detected pore" sizes for sample 1 (grey) and sample 2 (black) with 6- $\mu \mathrm{m}$ CT scan of reducing the area scanned in order to obtain a much smaller voxel size that would allow the identification of small light constituents (including pores), but could also not reliably represent the porosity distribution in the whole sample as in Salarian, Toyserkani [46], with DCM, it was possible to distinguish a high number of light constituents (including pores) below the scan resolution. These light constituents could not be detected with the conventional thresholding techniques, even when a lower voxel size (4 $\mu \mathrm{m}$ ) was employed. Because of the capacity to detect small defects, the level of porosity obtained with DCM for sample $1(0.019 \%)$ is greater than the corresponding values using CTan $(0.000 \%$ for manual thresholding) and VGStudio (0.004\% with VGDefX).

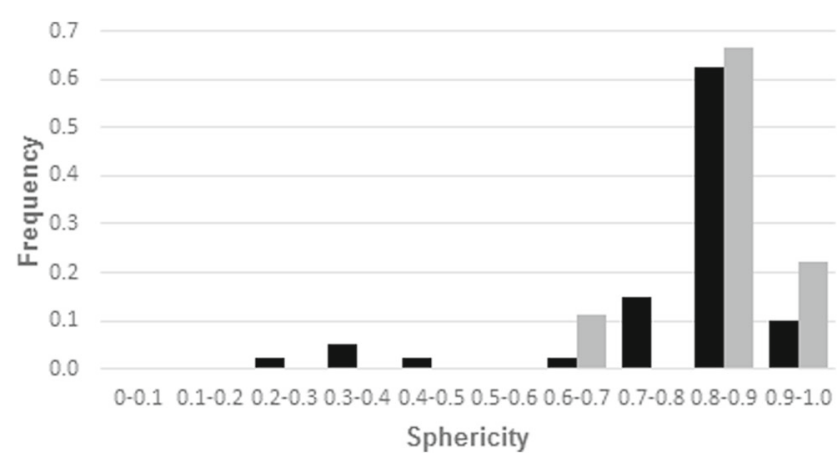

Fig. 8 Sphericity for sample 1 (grey) and sample 2 (black) with $6-\mu \mathrm{m}$ CT scan 

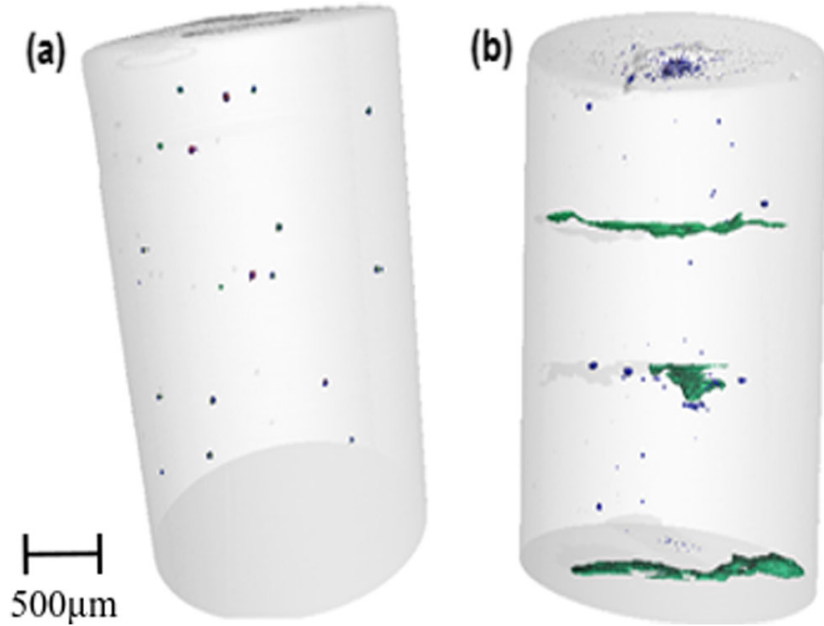

Fig. 9 3D visualisation of samples 1 (a) and 2 (b) in VGStudio. Bulk material is displayed in grey and "detected pores" are assigned different colours based on their relative size

Du Plessis et al. [35] has suggested a "general rule" that the minimum pore size that can be reliably identified is at least three voxels wide, which would justify the fact that no pores below $12 \mu \mathrm{m}$ were found with the $4-\mu \mathrm{m}$ voxel size of the second lab-based CT. It is worth mentioning that the inability to detect small pores has led Ziółkowski et al. [52] to conclude that the majority of pores in the samples considered were large and irregular. Notice that a similar conclusion could have been drawn by solely evaluating the latter scan (Figs. 10 and 11). However, we point out that, while DCM allows the determination of light constituent (including pore) sizes smaller than a voxel by calculating an upper-bound for the diameter of the sphere with equivalent volume, it is not possible to quantify light constituent shapes (and consequently sphericity) at a subvoxel resolution. Therefore, a reasonable volume threshold has to be determined above which surface area can be determined.

Furthermore, DCM allows to differentiate between oxides/carbides and light constituents (including pores).

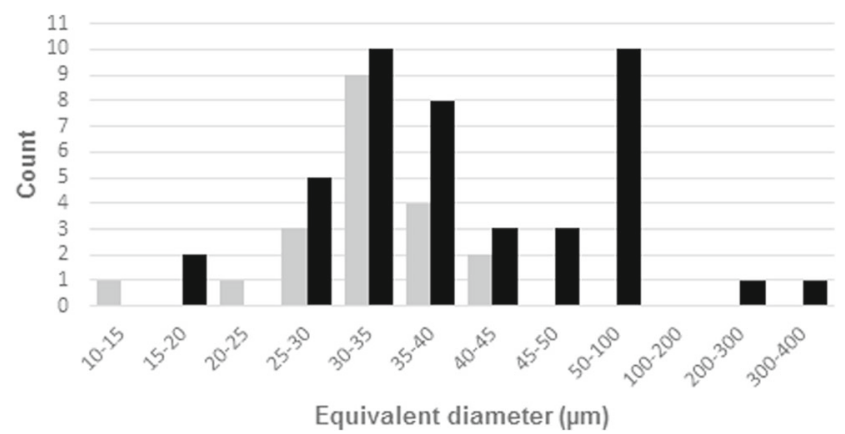

Fig. 10 "Detected pore" sizes for sample 1 (grey) and sample 2 (black) with a $4-\mu \mathrm{m}$ CT scan

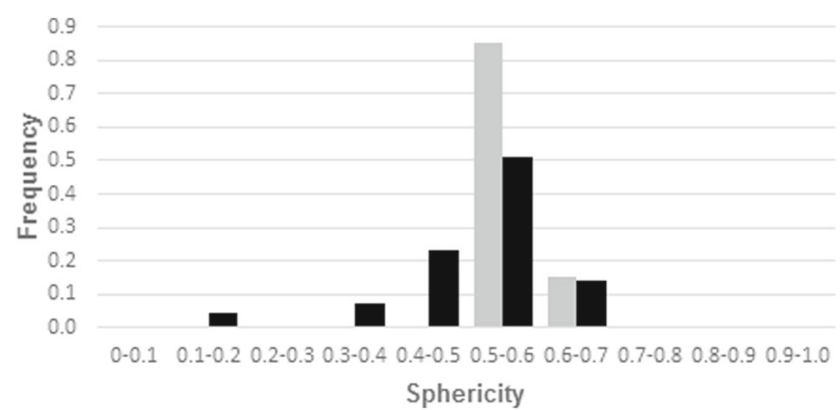

Fig. 11 Sphericity for sample 1 (grey) and sample 2 (black) with a 4- $\mu \mathrm{m}$ CT scan

Since the porosity level in the conventional CT scans also incorporates the interlayer oxides and carbides, this resulted in the porosity levels for sample $2(0.381 \%$ for manual thresholding with CTan and $0.306 \%$ with VGDefX) being higher than the value determined with DCM $(0.281 \%)$.

\subsection{Archimedes method, hardness test and SEM/EDS analysis}

In order to obtain an overall value for the porosity in the samples, the Archimedes method was used with a $\pm 0.1-\mathrm{mg}$ accuracy balance. The density of water was corrected based on the temperature [68]. As recommended by [67], some care was taken to ensure that air bubbles were not present on the samples during measurements (e.g. distilled water), the balance was re-zeroed before each measurement and the enclosure was shut to prevent air currents from affecting the measurement. However, in this study, the Archimedes method has failed to determine reliable results for the density measurements. This could be associated with the small sample sizes (approximately $0.135 \mathrm{~g}$ and $0.136 \mathrm{~g}$ for samples 1 and 2, respectively) and the presence of multiple phases with different densities in the samples. Because the buoyance force is too small, the variation between the mass of the samples in air and the mass of the samples in water is too small, resulting in extremely high density values (> $300 \mathrm{~g} / \mathrm{cm}^{3}$ ) that are not a true representation of the AM part.

The hardness test reveals that sample 1 has a uniform hardness, with values around $210 \mathrm{HV}$. In contrast, the hardness in sample 2 increases along the build direction from approximately $190 \mathrm{HV}$ to $225 \mathrm{HV}$ (Fig. 12). These high hardness values are in agreement with those discussed in the metal AM literature (Table 4) and result from the fine microstructure of the material as a result of fast cooling $[2,4,5]$. The increase in hardness for sample 2 could be correlated with the level of porosity since, except for the peaks of interlayer porosity, the porosity in the second specimen decreases in the build direction (Fig. 3), which could be responsible for the higher hardness observed [26]. It is important to note that the high levels of defects within 
Fig. 12 Hardness for sample 1 (blue) and sample 2 (red)

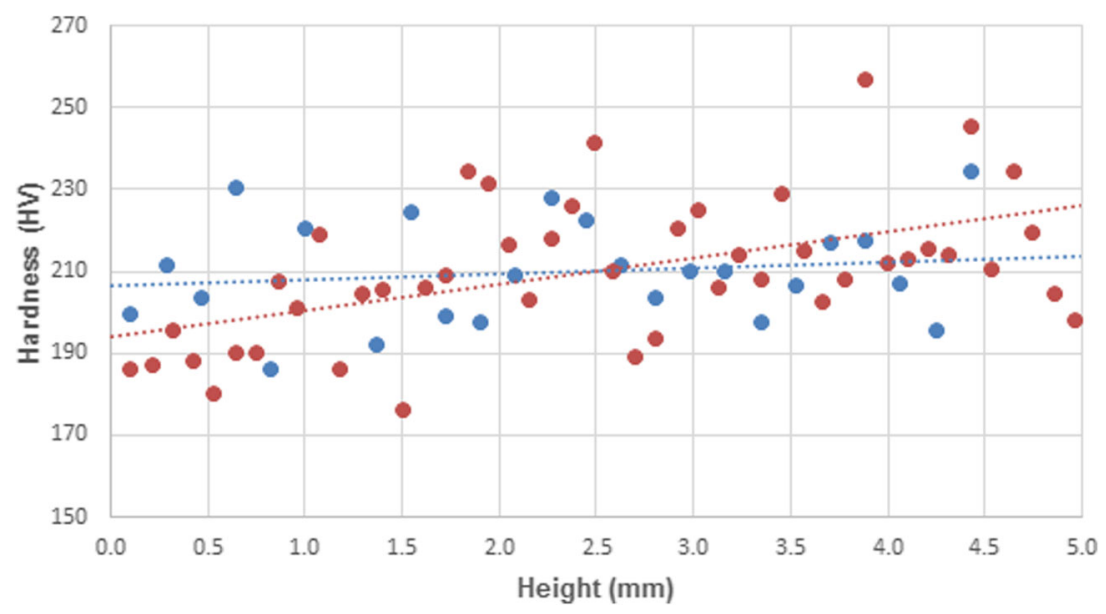

the layers in sample 2 did not directly translate into lower hardness values at the corresponding locations.

A related point to consider is the effect of defects in other mechanical properties. As discussed in the AM literature, cracks have been shown to initiate at pre-existing voids, and there is a strong correlation between the distribution of defects and the fatigue performance [73, 74]. Using finite element models (FEM), Neikter et al. [75] found large stress concentrations close to the defects, which are then more prone to initiation of cracks and fatigue failure. Consequently, the higher level of porosity and inclusions in sample 2, especially considering the irregular shape of the large defects, may result in poor fatigue performance.

Since sample 2 exhibited a significant level of inclusions between the layers, one of the interlayer regions was selected for further analysis. EDS of this location (Fig. 13) reveals that the inclusions are rich in silicon, manganese, chromium and oxygen. The presence of oxide inclusions rich in $\mathrm{Si}$ and $\mathrm{Mn}$ has also been reported in [65, 76, 77], whilst chromium oxide appeared in [78]. According to Simonelli et al. [77], this is a consequence of the high oxidation potential of these elements (especially $\mathrm{Si}$ and $\mathrm{Mn}$ ), as can be seen by the Ellingham diagram. Chromium and manganese carbides are also observed in the interlayer region, which are both well-established carbides in steel [79]. Furthermore, immersed in the inclusions,

Table 4 Hardness for 316L stainless steel parts built with MAM

\begin{tabular}{lll}
\hline Reference & Process & Hardness (HV) \\
\hline Mahmood and Pinkerton [69] & LMD & $175-210$ \\
Yadollahi et al. [70] & LMD & $150-227$ \\
Ziętala et al. [71] & LENS & $237-307$ \\
Yusuf et al. [14] & SLM & $237-262$ \\
Kurzynowski et al. [13] & SLM & $202-255$ \\
Liverani et al. [72] & SLM & $210-240$ \\
\hline
\end{tabular}

unmelted powder has remained (two of these are outlined by the red arrows and circles in the $\mathrm{Fe}$ image). It is noteworthy that EDS data comes in agreement with DCM in the prediction of oxides and carbides, whereas with conventional thresholding, those regions would probably be associated with large lack of fusion pores.

Investigation of the samples with the SEM at higher magnification reveals the presence of small spherical pores with sizes below $12 \mu \mathrm{m}$ uniformly distributed in the specimens, which cannot be reliably detected with the CT scan at $6 \mu \mathrm{m}$ using traditional thresholding. Considering ten randomly selected regions of approximately $30,000 \mu \mathrm{m}^{2}$ (magnification of 1600) in the polished surface, on average, 0.5 pore between $\sim 5-12 \mu \mathrm{m}$ was found in each region in sample 2 (for sample 1, a single pore above $5 \mu \mathrm{m}$ was present in the whole polished surface), whereas on average, 4 pores between $\sim 2-5 \mu \mathrm{m}$ were found in each region for both samples. Two of the pores below $12 \mu \mathrm{m}$ in sample 2 are shown in Fig. 14 with approximate sizes of $2.5 \mu \mathrm{m}$ and $10 \mu \mathrm{m}$. EDS analysis shows that they have high concentration of oxygen and, therefore, are a result of gas porosity, possibly associated with the low-packing density of metal powders or as a consequence of gas atomisation $[37,80]$. In Fig. 14, the EDS images for the $10 \mu \mathrm{m}$ pore are exposed; from them, it is seen that the void is also rich in silicon and manganese due to their strong affinity with oxygen. The same behaviour was exhibited by the $2.5-\mu \mathrm{m}$ pore.

It is important to point out that even though DCM allows the determination of defect sizes below CT resolution, with the noise threshold of 0.1 for the minimal volume fraction of light constituents (including pores) in the voxel, the smallest light constituent that can be detected is $3.44 \mu \mathrm{m}$. Thus, in order to study the light constituents below this limit (as the $2.5 \mu \mathrm{m}$ pore shown in Fig. 14), a higher resolution scan would be required. As a matter of fact, considering the noise threshold of 0.1 , the smallest volume feature $\left(V_{\min }\right)$ 

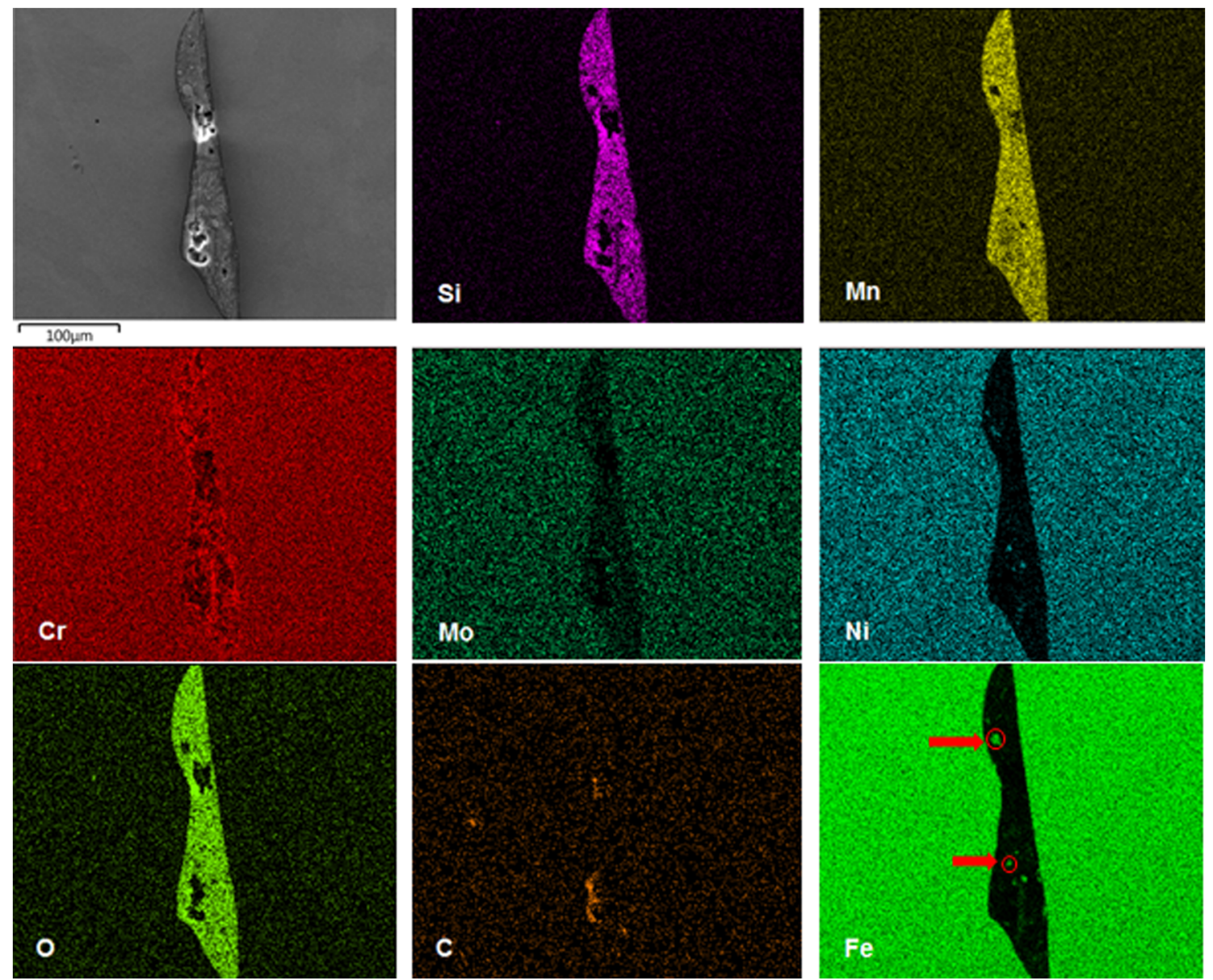

Fig. 13 EDS analysis of interlayer inclusions in sample 2
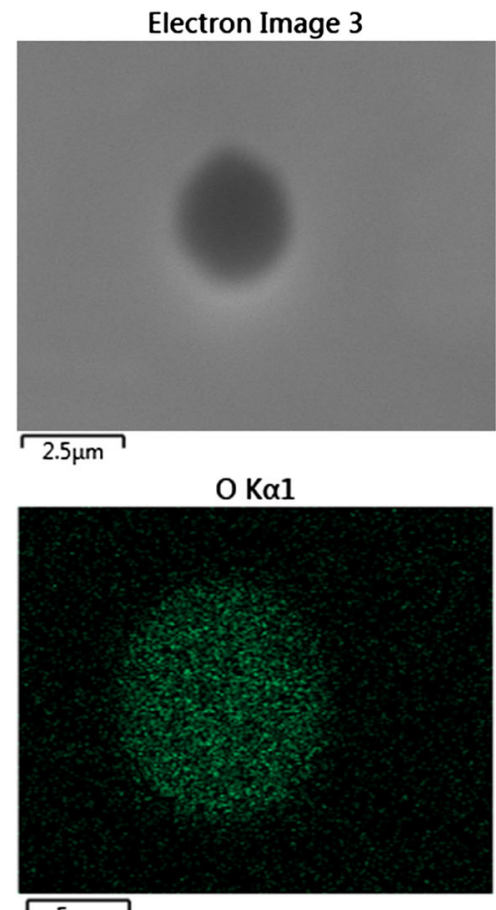

$\longdiv { 5 \mu m }$
Electron Image 5

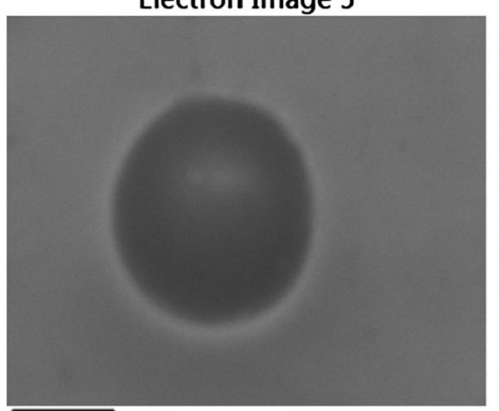

Si K $\alpha 1$

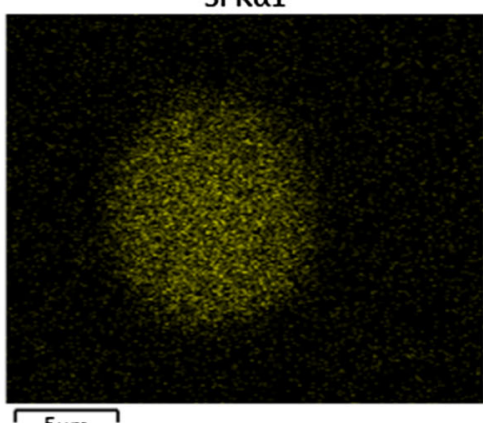

$\longdiv { 5 \mu \mathrm { m } }$
Fe K $\alpha 1$

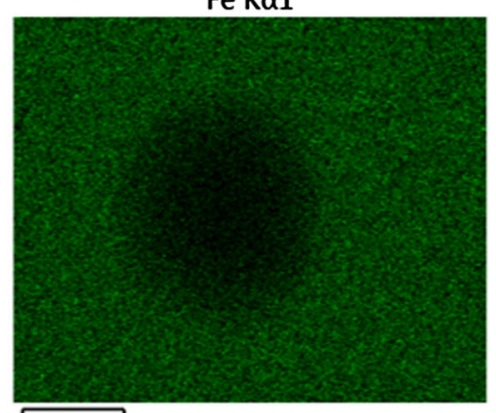

$\mathrm{Mn} \mathrm{K \alpha 1}$

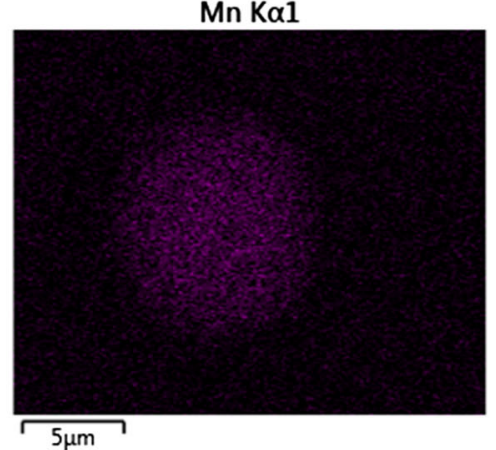

Fig. 14 EDS analysis of small pores in sample 2 
that can be detected is $0.1 x^{3}$, where $x$ is the voxel size. Consequently, the smallest equivalent spherical diameter $\left(D_{\min }\right)$ that can be detected with DCM is as follows:

$D_{\min }=\left(\frac{6 \cdot V_{\min }}{\pi}\right)^{1 / 3} \Rightarrow D_{\min } \approx 0.5759 x$

This is an obvious improvement from the smallest defect size detectable with traditional thresholding techniques.

\section{Conclusion}

In this paper, we have demonstrated that the use of DCM enhances the performance of quantitative analysis of defects in nondestructive testing using computed tomography. The method allows the determination of sub-voxel volume compositions and, consequently, the determination of defect sizes below CT resolution. It outperforms traditional thresholding algorithms even when performed with CT datasets at higher resolution (lower voxel size), providing a reliable method to determine the correct level of light constituents (as porosity) in additively manufactured metal parts. In contrast, we show that care must be taken when employing automatic thresholding techniques provided by different $3 \mathrm{D}$ visualisation and analysis software since these have indicated lack of robustness in the presence of low levels of porosity or material compositions with similar attenuations.

Using CT, one of the samples reveals a quite uniform distribution of defects with the light constituents (including pores) being small and spherical and, consequently, uniform mechanical properties. In contrast, the second sample had a high amount of interlayer inclusions (oxides and carbides) with light constituents being correlated with regions in which inclusions were also present. Some of these light constituents (including pores) were large and with irregular shape; therefore, they can act as stress concentration areas, are more susceptible to initiation of cracks and reduce fatigue life of the part. This behaviour was a result of oxidation occurring during cooling of the layers since the melting area is only shielded from the environment during powder deposition and was more pronounced in the proximity of the mild steel build plate, resulting in decreased hardness for lower heights.

\footnotetext{
Acknowledgments The authors acknowledge the facilities, and the scientific and technical assistance, of the RMIT Microscopy \& Microanalysis Facility, at RMIT University. We thank Romar Engineering and the Imaging and Medical beamline (IMBL) at the Australian Synchrotron for the sample preparation and image acquisition, respectively. The authors would also like to thank Sherry Mayo for assistance in synchrotron CT data acquisition, Joe Elambasseril for support with the conventional CT scans, Clement Chu for help in computational code implementation, and Tony Murphy for useful discussions.
}

Open Access This article is distributed under the terms of the Creative Commons Attribution 4.0 International License (http:// creativecommons.org/licenses/by/4.0/), which permits unrestricted use, distribution, and reproduction in any medium, provided you give appropriate credit to the original author(s) and the source, provide a link to the Creative Commons license, and indicate if changes were made.

\section{References}

1. Brandt M (2016) Laser additive manufacturing: Materials, design, technologies, and applications. Woodhead Publishing

2. Dutta B, Froes FH (2016) Additive manufacturing of titanium alloys: state of the art, Challenges and Opportunities. ButterworthHeinemann. https://doi.org/10.1016/C2015-0-02470-4

3. Gibson I, Rosen DW, Stucker B (2010) Additive manufacturing technologies: rapid prototyping to direct digital manufacturing. Springer, New York. https://doi.org/10.1007/978-1-4419-1120-9

4. Frazier WE (2014) Metal additive manufacturing: a review. J Mater Eng Perform 23(6):1917-1928. https://doi.org/10.1007/ s11665-014-0958-z

5. Herzog D, Seyda V, Wycisk E, Emmelmann C (2016) Additive manufacturing of metals. Acta Mater 117:371-392. https://doi.org/10.1016/j.actamat.2016.07.019

6. Sing SL, An J, Yeong WY, Wiria FE (2016) Laser and electronbeam powder-bed additive manufacturing of metallic implants: a review on processes, materials and designs. J Orthop Res 34(3):369-385. https://doi.org/10.1002/jor.23075

7. Tan XP, Tan YJ, Chow CSL, Tor SB, Yeong WY (2017) Metallic powder-bed based 3D printing of cellular scaffolds for orthopaedic implants: a state-of-the-art review on manufacturing, topological design, mechanical properties and biocompatibility. Mater Sci Eng C 76:1328-1343. https://doi.org/10.1016/j.msec.2017.02. 094

8. Arcella FG, Froes FH (2000) Producing titanium aerospace components from powder using laser forming. JOM 52(5):28-30. https://doi.org/10.1007/s11837-000-0028-x

9. Uriondo A, Esperon-Miguez M, Perinpanayagam S (2015) The present and future of additive manufacturing in the aerospace sector: a review of important aspects. Proceedings of the Institution of Mechanical Engineers, Part G: Journal of Aerospace Engineering 229(11):2132-2147. https://doi.org/10.1177/0954410014568797

10. Zhao C, Fezzaa K, Cunningham RW, Wen H, De Carlo F, Chen L, Rollett AD, Sun T (2017) Real-time monitoring of laser powder bed fusion process using highspeed X-ray imaging and diffraction. Scientific Reports 7(1). https://doi.org/10.1038/s41598-017-03761-2

11. Zhou X, Wang D, Liu X, Zhang D, Qu S, Ma J, London G, Shen Z, Liu W (2015) 3D-imaging of selective laser melting defects in a Co-Cr-Mo alloy by synchrotron radiation micro-CT. Acta Materialia 98:1-16. https://doi.org/10.1016/j.actamat.2015.07.014

12. Bayode A, Akinlabi ET, Pityana S (2016) Characterization of laser metal deposited 316L stainless steel. In: Lecture Notes in Engineering and Computer Science, pp 925-928

13. Kurzynowski T, Gruber K, Stopyra W, Kuźnicka B, Chlebus E (2018) Correlation between process parameters, microstructure and properties of 316L stainless steel processed by selective laser melting. Mater Sci Eng A 718:64-73. https://doi.org/10.1016/j.msea.2018.01.103

14. Yusuf SM, Chen Y, Boardman R, Yang S, Gao N (2017) Investigation on porosity and microhardness of $316 \mathrm{~L}$ stainless steel fabricated by selective laser melting. Metals 7(2). https://doi.org/10.3390/met7020064 
15. Koester LW, Taheri H, Bigelow TA, Collins PC, Bond LJ (2018) Nondestructive testing for metal parts fabricated using powderbased additive manufacturing. Mater Eval 76(4):514-524

16. Murr LE, Gaytan SM, Ramirez DA, Martinez E, Hernandez J, Amato KN, Shindo PW, Medina FR, Wicker RB (2012) Metal fabrication by additive manufacturing using laser and electron beam melting technologies. J Mater Sci Technol 28(1):1-14. https://doi.org/10.1016/S1005-0302(12)60016-4

17. Chua ZY, Ahn IH, Moon SK (2017) Process monitoring and inspection systems in metal additive manufacturing: status and applications. International Journal of Precision Engineering and Manufacturing - Green Technology 4(2):235-245. https://doi.org/10.1007/s40684-017-0029-7

18. Lu QY, Wong CH (2018) Additive manufacturing process monitoring and control by non-destructive testing techniques: challenges and in-process monitoring. Virtual Phys Prototy 13(2):39-48. https://doi.org/10.1080/17452759.2017.1351201

19. Slotwinski JA (2014) Additive manufacturing: overview and NDE challenges. In: AIP Conference Proceedings, pp 1173-1177. https://doi.org/10.1063/1.4864953

20. Tapia G, Elwany A (2014) A review on process monitoring and control in metal-based additive manufacturing. Journal of manufacturing science and engineering. Transactions of the ASME 136(6). https://doi.org/10.1115/1.4028540

21. Gong H, Rafi K, Gu H, Janaki Ram GD, Starr T, Stucker B (2015) Influence of defects on mechanical properties of Ti-6Al-4V components produced by selective laser melting and electron beam melting. Mater Des 86:545-554. https://doi.org/10.1016/j.matdes.2015.07.147

22. Lewandowski JJ, Seifi M (2016) Metal additive manufacturing: a review of mechanical properties. Annu Rev Mater Res 46. https://doi.org/10.1146/annurev-matsci-070115-032024

23. Siddique S, Imran M, Rauer M, Kaloudis M, Wycisk E, Emmelmann C, Walther F (2015) Computed tomography for characterization of fatigue performance of selective laser melted parts. Mater Des 83:661-669. https://doi.org/10.1016/j.matdes.2015.06.063

24. Tammas-Williams S, Withers PJ, Todd I, Prangnell PB (2017) The influence of porosity on fatigue crack initiation in additively manufactured titanium components. Scientific Reports 7(1). https://doi.org/10.1038/s41598-017-06504-5

25. Wang $\mathrm{P}$, Tan X, He C, Nai MLS, Huang R, Tor SB, Wei J (2018) Scanning optical microscopy for porosity quantification of additively manufactured components. Addit Manuf 21:350-358. https://doi.org/10.1016/j.addma.2018.03.019

26. Wits WW, Carmignato S, Zanini F, Vaneker THJ (2016) Porosity testing methods for the quality assessment of selective laser melted parts. CIRP Ann Manuf Technol 65(1):201-204. https://doi.org/10.1016/j.cirp.2016.04.054

27. Spierings AB, Schneider M, Eggenberger R (2011) Comparison of density measurement techniques for additive manufactured metallic parts. Rapid Prototyp J 17(5):380-386. https://doi.org/10.1108/13552541111156504

28. Ahsan MN, Bradley R, Pinkerton AJ (2011) Microcomputed tomography analysis of intralayer porosity generation in laser direct metal deposition and its causes. J Laser Appl 23(2)

29. Maskery I, Aboulkhair NT, Corfield MR, Tuck C, Clare AT, Leach RK, Wildman RD, Ashcroft IA, Hague RJM (2016) Quantification and characterisation of porosity in selectively laser melted AlSi10-Mg using X-ray computed tomography. Mater Charact 111:193-204. https://doi.org/10.1016/j.matchar.2015.12.001

30. Caputo D, Aprea P, Gargiulo N, Liguori B (2017) The role of materials and products characterization in the additive manufacturing industry. In: RTSI 2017 - IEEE 3Rd International Forum on Research and Technologies for Society and Industry, Conference Proceedings. https://doi.org/10.1109/RTSI.2017.8065965
31. Rieder H, Dillhöfer A, Spies M, Bamberg J, Hess T (2014) Online monitoring of additive manufacturing processes using ultrasound. In: 11th European Conference on Nondestructive Testing (ECNDT), Prague, Czech Republic, pp 610

32. Rieder H, Spies M, Bamberg J, Henkel B (2016) On-and offline ultrasonic inspection of additively manufactured components. In: 19th World Conference on Non-destructive Testing (WCNDT), Munich, Germany, pp 13-17

33. Aleshin NP, Grigor'ev MV, Shchipakov NA, Prilutskii MA, Murashov VV (2016) Applying nondestructive testing to quality control of additive manufactured parts. Russ J Nondestruct Test 52(10):600-609. https://doi.org/10.1134/S1061830916100028

34. Thompson A, Maskery I, Leach RK (2016) X-ray computed tomography for additive manufacturing: a review. Meas Sci Technol 27(7). https://doi.org/10.1088/0957-0233/27/7/072001

35. du Plessis A, Yadroitsev I, Yadroitsava I, Le Roux SG (2018) $\mathrm{X}$-ray microcomputed tomography in additive manufacturing: a review of the current technology and applications. 3D Printing and Additive Manufacturing

36. Cai X, Malcolm AA, Wong BS, Fan Z (2015) Measurement and characterization of porosity in aluminium selective laser melting parts using X-ray CT. Virtual Phys Prototy 10(4):195206. https://doi.org/10.1080/17452759.2015.1112412

37. Cunningham R, Narra SP, Ozturk T, Beuth J, Rollett $\mathrm{AD}$ (2016) Evaluating the effect of processing parameters on porosity in electron beam melted Ti-6Al-4V via synchrotron X-ray microtomography. JOM 68(3):765-771. https://doi.org/10.1007/s11837-015-1802-0

38. De Chiffre L, Carmignato S, Kruth JP, Schmitt R, Weckenmann A (2014) Industrial applications of computed tomography. CIRP Ann Manuf Technol 63(2):655-677. https://doi.org/10.1016/j.cirp.2014.05.011

39. Flannery BP, Deckman HW, Roberge WG, D'Amico KL (1987) Three-dimensional X-ray microtomography. Science 237(4821):1439-1444. https://doi.org/10.1126/science.237.4821. 1439

40. Maire E, Withers PJ (2014) Quantitative X-ray tomography. Int Mater Rev 59(1):1-43. https://doi.org/10.1179/1743280413Y. 0000000023

41. Maire E, Buffière JY, Salvo L, Blandin JJ, Ludwig W, Létang JM (2001) On the application of X-ray microtomography in the field of materials science. Adv Eng Mater 3(8):539_ 546. https://doi.org/10.1002/1527-2648(200108)3:8<539::AIDADEM539>3.0.CO;2-6

42. Stock SR (2008) Recent advances in X-ray microtomography applied to materials. Int Mater Rev 53(3):129-181. https://doi.org/10.1179/174328008X277803

43. Hanke R, Fuchs T, Salamon M, Zabler S (2016) X-ray microtomography for materials characterization. In: Materials Characterization Using Nondestructive Evaluation (NDE) Methods, pp 45-79. https://doi.org/10.1016/B978-0-08-100040-3.00003-1

44. Landis EN, Keane DT (2010) X-ray microtomography. Mater Charact 61(12):1305-1316. https://doi.org/10.1016/j.matchar. 2010.09.012

45. Tammas-Williams S, Zhao H, Léonard F, Derguti F, Todd I, Prangnell PB (2015) XCT Analysis of the influence of melt strategies on defect population in Ti-6Al-4V components manufactured by Selective Electron Beam Melting. Mater Charact 102:47-61. https://doi.org/10.1016/j.matchar.2015.02.008

46. Salarian M, Toyserkani E (2018) The use of nano-computed tomography (nano-CT) in non-destructive testing of metallic parts made by laser powder-bed fusion additive manufacturing. International Journal of Advanced Manufacturing Technology. https://doi.org/10.1007/s00170-018-2421-z 
47. Baruchel J, Buffiere JY, Cloetens P, Di Michiel M, Ferrie E, Ludwig W, Maire E, Salvo L (2006) Advances in synchrotron radiation microtomography. Scr Mater 55(1 SPEC. ISS.):41-46. https://doi.org/10.1016/j.scriptamat.2006.02.012

48. Thompson AC, Llacer J, Campbell Finman L, Hughes EB, Otis JN, Wilson S, Zeman HD (1984) Computed tomography using synchrotron radiation. Nuclear Instruments and Methods In Physics Research 222(1-2):319-323. https://doi.org/10.1016/0167-5087(84)90550-7

49. Di Michiel M, Merino JM, Fernandez-Carreiras D, Buslaps T, Honkimäki V, Falus P, Martins T, Svensson O (2005) Fast microtomography using high energy synchrotron radiation. Rev Sci Instrum 76(4). https://doi.org/10.1063/1.1884194

50. Yang YS, Tulloh AM, Muster T, Trinchi A, Mayo SC (2010) Wilkins SW Data-constrained microstructure modeling with multi-spectrum X-ray CT. In: Proceedings of SPIE - The International Society for Optical Engineering. https://doi.org/10.1117/12.861964

51. Trinchi A, Yang YS, Huang JZ, Falcaro P, Buso D, Cao LQ (2012) Study of 3D composition in a nanoscale sample using data-constrained modelling and multienergy X-ray CT. Model Simul Mater Sci Eng 20(1). https://doi.org/10.1088/0965-0393/20/1/015013

52. Ziółkowski G, Chlebus E, Szymczyk P, Kurzac J (2014) Application of X-ray CT method for discontinuity and porosity detection in $316 \mathrm{~L}$ stainless steel parts produced with SLM technology. Arch Civ Mech Eng 14(4):608-614. https://doi.org/10.1016/j.acme.2014.02.003

53. Yang YS, Wang H, Gao J (2012) A data-constrained modelling approach to materials microstructure characterisation. Journal of Shanxi University 35(2):248-254

54. Yang YS (2012) A data-constrained non-linear optimization approach to compositional microstructure characterization. In: Zhu M (ed) 2nd International Conference on Materials, Mechatronics and Automation, Nanching, China, May 7-8, 2012, pp 198-205

55. Yang YS, Liu KY, Mayo S, Tulloh A, Clennell MB, Xiao TQ (2013) A data-constrained modelling approach to sandstone microstructure characterisation. J Pet Sci Eng 105:76-83. https://doi.org/10.1016/j.petrol.2013.03.016

56. Wang $\mathrm{Y}$, Liu K, Yang Y, Ren Y, Hu T, Deng B, Xiao T (2016) Quantitative multi-scale analysis of mineral distributions and fractal pore structures for a heterogeneous Junger Basin shale. J Instrum 11(04):C04005

57. Wang YD, Yang YS, Cole I, Trinchi A, Xiao TQ (2013) Investigation of the microstructure of an aqueously corroded zinc wire by data-constrained modelling with multi-energy X-ray CT. Mater Corros 64(3):180-184. https://doi.org/10.1002/maco.201106341

58. Ren YQ, King PC, Yang YS, Xiao TQ, Chu C, Gulizia S, Murphy AB (2017) Characterization of heat treatment-induced pore structure changes in cold-sprayed titanium. Mater Charact 132:69-75. https://doi.org/10.1016/j.matchar.2017.08.006

59. Gureyev TE, Nesterets Y, Ternovski D, Thompson D, Wilkins SW, Stevenson AW, Sakellariou A, Taylor JA (2011) Toolbox for advanced X-ray image processing. In: Proceedings of SPIE - The International Society for Optical Engineering. https://doi.org/10.1117/12.893252

60. Paganin D, Mayo SC, Gureyev TE, Miller PR, Wilkins SW (2002) Simultaneous phase and amplitude extraction from a single defocused image of a homogeneous object. J Microsc 206(1):3340. https://doi.org/10.1046/j.1365-2818.2002.01010

61. Banhart J (2008) Advanced tomographic methods in materials research and engineering. Oxford University Press, Oxford

62. Perry DL (2011) Handbook of inorganic compounds, 2nd edn. Taylor \& Francis, Boca Raton
63. Iassonov P, Gebrenegus T, Tuller M (2009) Segmentation of X-ray computed tomography images of porous materials: a crucial step for characterization and quantitative analysis of pore structures. Water Resour Res 45(9). https://doi.org/10.1029/2009WR008087

64. Sheppard AP, Sok RM, Averdunk H (2004) Techniques for image enhancement and segmentation of tomographic images of porous materials. Physica A: Statistical Mechanics and its Applications 339(1-2):145-151. https://doi.org/10.1016/j.physa.2004.03.057

65. Lou X, Andresen PL, Rebak RB (2018) Oxide inclusions in laser additive manufactured stainless steel and their effects on impact toughness and stress corrosion cracking behavior. J Nucl Mater 499:182-190. https://doi.org/10.1016/j.jnucmat.2017.11.036

66. Rao S, Cunningham R, Ozturk T, Rollett AD (2016) Measurement and analysis of porosity in Al-10Si-1Mg components additively manufactured by selective laser melting. Materials Performance and Characterization 5(5):701-716. https://doi.org/10.1520/MPC20160037

67. Slotwinski JA, Garboczi EJ, Hebenstreit KM (2014) Porosity measurements and analysis for metal additive manufacturing process control. Journal of Research of the National Institute of Standards and Technology 119:494-528. https://doi.org/10.6028/jres.119.019

68. Haynes WM (2016) CRC Handbook of Chemistry and Physics. 97 edn. CRC Press

69. Mahmood K, Pinkerton AJ (2013) Direct laser deposition with different types of 316L steel particle: a comparative study of final part properties. Proceedings of the Institution of Mechanical Engineers, Part B: Journal of Engineering Manufacture 227(4):520_ 531. https://doi.org/10.1177/0954405413475961

70. Yadollahi A, Shamsaei N, Thompson SM, Seely DW (2015) Effects of process time interval and heat treatment on the mechanical and microstructural properties of direct laser deposited 316L stainless steel. Mater Sci Eng A 644:171-183. https://doi.org/10.1016/j.msea.2015.07.056

71. Ziętala M, Durejko T, Polański M, Kunce I, Płociński T, Zieliński W, Łazińska M, Stepniowski W, Czujko T, Kurzydłowski KJ, Bojar Z (2016) The microstructure, mechanical properties and corrosion resistance of $316 \mathrm{~L}$ stainless steel fabricated using laser engineered net shaping. Mater Sci Eng A 677:1-10. https://doi.org/10.1016/j.msea.2016.09.028

72. Liverani E, Toschi S, Ceschini L, Fortunato A (2017) Effect of selective laser melting (SLM) process parameters on microstructure and mechanical properties of $316 \mathrm{~L}$ austenitic stainless steel. J Mater Process Technol 249:255-263. https://doi.org/10.1016/j.jmatprotec.2017.05.042

73. Carlton HD, Haboub A, Gallegos GF, Parkinson DY, Macdowell AA (2016) Damage evolution and failure mechanisms in additively manufactured stainless steel. Mater Sci Eng A 651:406414. https://doi.org/10.1016/j.msea.2015.10.073

74. Leuders S, Thöne M, Riemer A, Niendorf T, Tröster T, Richard HA, Maier HJ (2012) On the mechanical behaviour of titanium alloy TiAl6V4 manufactured by selective laser melting: fatigue resistance and crack growth performance. Int $\mathrm{J}$ Fatigue 48. https://doi.org/10.1016/j.ijfatigue.2012.11.011

75. Neikter M, Forsberg F, Pederson R, Antti M-L, ÃĚkerfeldt P, Larsson S, Jonsén P, Puyoo G (2018) Defect characterization of electron beam melted Ti-6Al-4V and Alloy 718 with Xray microtomography. Aeronautics and Aerospace Open Access Journal 2(3):139-145

76. Gorsse S, Hutchinson C, Gouné M, Banerjee R (2017) Additive manufacturing of metals: a brief review of the characteristic microstructures and properties of steels, Ti-6Al-4V and high-entropy alloys. Sci Technol Adv Mater 18(1):584-610. https://doi.org/10.1080/14686996.2017.1361305

77. Simonelli M, Tuck C, Aboulkhair NT, Maskery I, Ashcroft I, Wildman RD, Hague R (2015) A study on the laser spatter and the 
oxidation reactions during selective laser melting of 316L stainless steel, Al-Si10-Mg, and Ti-6Al-4V. Metallurgical and Materials Transactions A: Physical Metallurgy and Materials Science 46(9):3842-3851. https://doi.org/10.1007/s11661-015-2882-8

78. Saeidi K (2016) Stainless steels fabricated by laser melting. Sweden

79. Jack DH, Jack KH (1973) Invited review: carbides and nitrides in steel. Mater Sci Eng 11(1):1-27. https://doi.org/10.1016/00255416(73)90055-4
80. Zhang B, Li Y, Bai Q (2017) Defect formation mechanisms in selective laser melting: a review. Chinese Journal of Mechanical Engineering (English Edition) 30(3):515-527. https://doi.org/10. 1007/s10033-017-0121-5

Publisher's note Springer Nature remains neutral with regard to jurisdictional claims in published maps and institutional affiliations. 